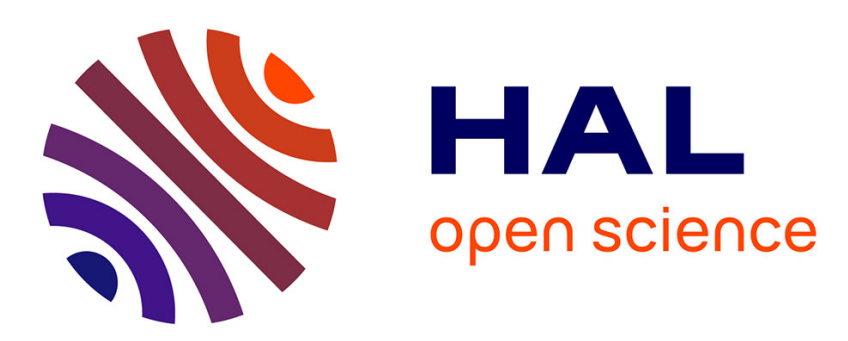

\title{
Glycomics Profiling of Heparan Sulfate Structure and Activity
}

Jeremy E Turnbull, Rebecca M Miller, Yassir Ahmed, Tania Puvirajesinghe, Scott E Guimond

\section{- To cite this version:}

Jeremy E Turnbull, Rebecca M Miller, Yassir Ahmed, Tania Puvirajesinghe, Scott E Guimond. Glycomics Profiling of Heparan Sulfate Structure and Activity. Methods in Enzymology, 2010, 480, pp.65-85. 10.1016/S0076-6879(10)80004-7 . hal-01447774

\section{HAL Id: hal-01447774 https://hal.science/hal-01447774}

Submitted on 27 Jan 2017

HAL is a multi-disciplinary open access archive for the deposit and dissemination of scientific research documents, whether they are published or not. The documents may come from teaching and research institutions in France or abroad, or from public or private research centers.
L'archive ouverte pluridisciplinaire HAL, est destinée au dépôt et à la diffusion de documents scientifiques de niveau recherche, publiés ou non, émanant des établissements d'enseignement et de recherche français ou étrangers, des laboratoires publics ou privés. 


\section{Provided for non-commercial research and educational use only. Not for reproduction, distribution or commercial use.}

This chapter was originally published in the book Methods in Enzymology, Vol. 480, published by Elsevier, and the attached copy is provided by Elsevier for the author's benefit and for the benefit of the author's institution, for non-commercial research and educational use including without limitation use in instruction at your institution, sending it to specific colleagues who know you, and providing a copy to your institution's administrator.

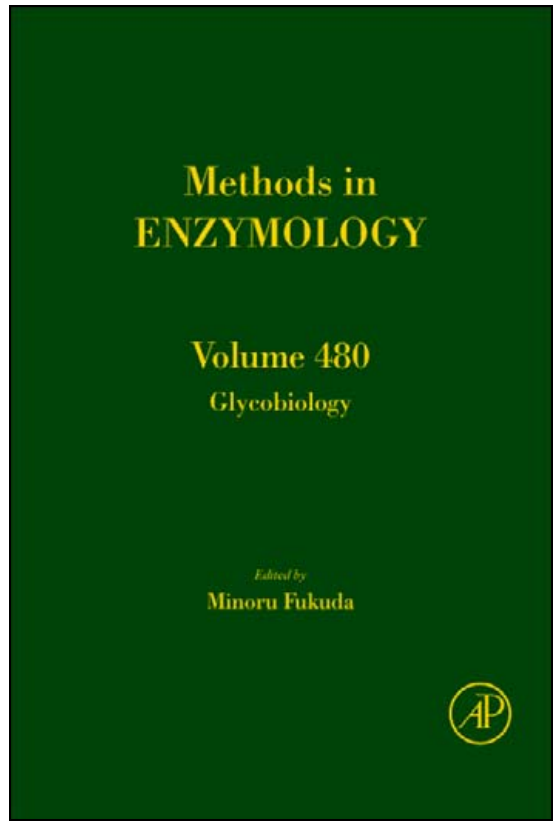

All other uses, reproduction and distribution, including without limitation commercial reprints, selling or licensing copies or access, or posting on open internet sites, your personal or institution's website or repository, are prohibited. For exceptions, permission may be sought for such use through Elsevier's permissions site at: http://www.elsevier.com/locate/permissionusematerial

From: Jeremy E. Turnbull, Rebecca L. Miller, Yassir Ahmed, Tania M. Puvirajesinghe, and Scott E. Guimond, Glycomics Profiling of Heparan Sulfate Structure and Activity. In Minoru Fukuda, editor: Methods in Enzymology, Vol. 480, Burlington: Academic Press, 2010, pp. 65-85.

ISBN: 978-0-12-380999-5

(C) Copyright 2010 Elsevier Inc. Academic Press. 


\title{
Glycomics Profiling of Heparan Sulfate Structure and Activity
}

\author{
Jeremy E. Turnbull, Rebecca L. Miller, Yassir Ahmed, \\ Tania M. Puvirajesinghe, and Scott E. Guimond
}

\section{Contents}

1. Overview

66

1.1. HS structure and biosynthesis

66

1.2. Heparan sulfates: A family of multifunctional cell regulators

67

1.3. Decoding HS structure-function: Toward glycomics approaches

68

69

69

2.1. Rapid purification of HS 70

2.2. Profiling disaccharide composition

2.3. Profiling HS oligosaccharides 73

$\begin{array}{ll}\text { 2.4. Profiling HS oligosaccharide function } & 77\end{array}$

3. Conclusions and Future Perspectives 81

$\begin{array}{ll}\text { Acknowledgments } & 81\end{array}$

$\begin{array}{lr}\text { References } & 81\end{array}$

\begin{abstract}
The heparan sulfate (HS) family of glycosaminoglycans are highly complex and structurally diverse polysaccharides with information encoded within the chains that imparts the ability to bind selectively to a wide range of proteins - the "HS interactome" - and to regulate their biological activities. However, there are two key questions which need to be addressed; first, the extent of structural variation of expressed HS structures-the "heparanome"-in specific biological contexts and second, the degree of functional selectivity exerted by these structures in regulating biological processes. There is a clear need to develop more systematic and high throughput approaches in order to address these questions. Here, we describe a cohort of protocols for profiling different aspects of HS structure and activity, focusing particularly on disaccharide building blocks and larger oligosaccharide domains, the latter representing the functional units of HS chains. A range of other complementary methods in the literature are also discussed. Together these provide a new and more
\end{abstract}

Centre for Glycobiology, School of Biological Sciences, University of Liverpool, Liverpool, United Kingdom

(C) 2010 Elsevier Inc. 
comprehensive toolkit to investigate HS structure and activity in a higher throughput manner in selected biological systems. The implementation of such a glycomics strategy will enable development of a systems biology view of HS structure-function relationships and help to resolve the significant puzzle of the extensive interactome of HS, which remains a key question in the glycobiology field. We anticipate that the next decade will see major advances in our understanding of the complex biology of HS.

\section{OVERVIEW}

\subsection{HS structure and biosynthesis}

Heparan sulfate (HS) is a member of the glycosaminoglycan (GAG) family of linear polysaccharides made up of repeating disaccharide unit backbones onto which are superimposed specific modification patterns, most notably addition of sulfate groups. Within this family, HS has the most highly varied structure, with polymorphic sulfated sequences expressed found in its chains which are responsible for the many protein binding and regulatory properties of HS (Turnbull et al., 2001). HS chains are normally attached to core proteins in the form of HS proteoglycans (HSPGs), which are located at the cell surface and in the extracellular matrix. HS biosynthesis involves a complex set of Golgi enzymes which initially produce a nonsulfated polysaccharide chain precursor, heparosan. A sequential series of modifications then follows which superimpose complex patterns of sulfate group addition and uronate epimerization at selective positions. Most important, the system is not template-driven and the reactions only proceed to a partial extent, resulting in a high degree of structural diversity of HS sugar sequences. There is an ordered structure to HS chains in which domains with differing types and density of modifications are spaced apart along the molecule (Turnbull and Gallagher, 1991). Domains where the heparosan has undergone relatively few modifications consist mainly of GlcA-GlcNAc repeats, and are called $\mathrm{N}$-acetylated (NA) domains. These act to space apart the highly modified, sulfated domains (S-domains; typically 3-8 disaccharide units in length) in which extensive modifications occur, especially $\mathrm{N}$ - and O-sulfate group additions and epimerization of glucuronic acid (GlcA) to iduronic acid (IdoA). Flanking domains that have alternating $\mathrm{N}$-acetylated and $N$-sulfated disaccharides (NA/NS domains) are also present (Lindahl et al., 1998; Turnbull et al., 2001).

Variant HS chain modifications provide structural diversity that underpins its many protein binding and regulatory properties. The potential variations in even short saccharide sequences are very high, making HS a very information dense molecule (Nugent, 2000), though the theoretical 
variations are restricted by biosynthetic constraints. Reproducible differences in HS structure have been observed at both the tissue (Brickman et al., 1998; Ford-Perriss et al., 2002; Maccarana et al., 1996) and cell level (Kato et al., 1994; Sanderson et al., 1994), and upon cell transformation (Jayson et al., 1998). Identical core proteins can display different HS structures when expressed by different cell types (Kato et al., 1994; Sanderson et al., 1994). Furthermore, it is increasingly evident that HS structures are biosynthesized in a dynamic manner: HSPGs have a rapid turnover (half-life 3-4 h) in cultured cells (Yanagishita and Hascall, 1984); cells can alter the HS structures they make, for example, in response to extracellular signals such as growth factors (Schmidt et al., 1995); and changes in HS structure have been shown to occur over short time spans in developing tissues (Ford-Perriss et al., 2002). HS is thus not as a single molecule but is in fact a highly diverse family of related molecules with dynamic and specific functional roles (Turnbull et al., 2001).

\subsection{Heparan sulfates: A family of multifunctional cell regulators}

The HS family is now viewed as multifunctional players with vital roles in cell regulation (Turnbull et al., 2001). Their strategic location at the cell surface and in the extracellular matrix, positions them ideally for selective regulatory interactions with many proteins (Ori et al. 2008; Powell et al., 2004). These interactions can result in functional regulation of protein activities and are critical for a range of physiological processes (Bishop et al., 2007). Genetic studies in model organisms have clearly demonstrated that HS is essential for many aspects of development and normal physiological functions (Lander and Selleck, 2000).

HS interacts with an extraordinary range of proteins (the HS "interactome") including growth factors, enzymes, extracellular matrix proteins, and proteins found on the surface of pathogens (Ori et al. 2008). In many examples of HS-protein interactions there is evidence that these interactions are selective to varying degrees and serve regulatory roles. A principal role of HS is to act as a "catalyst of molecular encounters" (Lander et al., 1999). The mechanisms of action of HS are an active area of investigation which has revealed a number of distinct modes of action in mediating protein-protein interactions, including altering protein conformations (e.g., antithrombin III), increasing protein stability and restricting protein mobility, acting as a cell surface receptor, and acting as a template for controlled assembly of protein complexes (Turnbull et al., 2001). Probably one of the best studied examples of the latter is the action of HS as a coreceptor for the fibroblast growth factor (FGF) family, where it modulates 
the interaction of FGF with its receptor tyrosine kinase (Ornitz et al., 1996; Rapraeger et al., 1991; Yayon et al., 1991). HS activates signaling by participating in the formation of a ternary complex, mediated by specific interactions of the HS with both the growth factor and its receptor, and the presence or absence of specific sulfate groups within HS can dictate which members of the FGF family can signal through which receptors (Guimond and Turnbull, 1999; Pye et al., 1998).

\subsection{Decoding HS structure-function: Toward glycomics approaches}

Two key questions in the field are now the extent of natural diversity of HS structures-the "heparanome"-in specific biological systems (Turnbull et al., 2001) and the level of sequence specificity or selectivity in terms of regulation of biological responses (Lindahl and Ping, 2009). It has become increasingly clear that HS does not influence protein functions in a "digital" on/off manner via highly specific single sequences with single functions, but rather via "analog tuning" in which ensembles of restricted motifs are able to exert a range of modulatory functions. Further work is now clearly required to decode HS structural diversity and how this relates to functional properties in a systematic manner. Glycomics technologies have recently been expanding in the wider glycobiology field (Turnbull and Field, 2007), and strategies appropriate for HS can now be envisaged which integrate a variety of methods in order to develop a systems biology view of the structural selectivity underlying the diverse functions of HSPGs.

The first step for this type of strategy is isolation of HS from the appropriate cells or tissues under study. Second, the "building blocks" present can be determined by quantitative disaccharide compositional analysis, permitting a first (basic) level of comparison of tissue and cell type specificity of HS structures. This is typically achieved using HPLC methods employing UV or fluorescence detection, or by mass spectrometry, using authentic standards. Third, and increasingly important, the higher order organization of disaccharide building blocks into oligosaccharide level domains can be profiled (or "mapped") using a variety of methods including gel electrophoresis, gel filtration, HPLC, and mass spectroscopy. Finally, it is also possible to profile the bioactivities of particular saccharides, allowing screening and determination of the functional specificity of particular saccharides. Here, we present protocols for a number of methods in this type of work flow and further information on additional alternative methods. 


\section{EXPERIMENTAL}

\subsection{Rapid purification of HS}

In order to study the variant spatial and temporal regulation of HS biosynthesis in cells and tissues, efficient methods for extraction of HS are required to facilitate subsequent structural analysis. Isolation of HS and other GAGs from tissues can be achieved through several means. The most common involves the dissolution of tissues using proteases, detergents, and/or chaotropic salts. Alkaline treatment of tissues can also be used to release GAG chains from their protein cores. The exact method used is chosen based on the amount and nature of the starting material and the availability of equipment and reagents. These methods for the isolation of HS are more suited to use on larger amounts of tissues or have multiple, lengthy steps. Previous methods could also suffer loss of material during transfer steps. Use of the recently developed RIP (Rapid Isolation of Proteoglycans) method to isolate HS from small cell or tissue samples overcomes these problems (Guimond et al., 2009).

\subsubsection{RIP method for isolation of proteoglycans}

1. Tissues are ground in a tissue homogenizer with $1 \mathrm{ml}$ of Trizol reagent for every $100 \mathrm{mg}$ of wet weight of starting tissue. The samples are left for $5 \mathrm{~min}$ at room temperature (RT), and then $0.2 \mathrm{ml}$ of chloroform is added per $1 \mathrm{ml}$ of Trizol originally used. Samples are shaken vigorously for $15 \mathrm{~s}$ and then left for $3 \mathrm{~min}$ at RT. Centrifuge samples at no more than $12,000 \times g$ for $15 \mathrm{~min}$ at $4{ }^{\circ} \mathrm{C}$.

2. Remove the upper, aqueous layer containing the proteoglycans as well as RNA. Dilute 1:10 in water and apply to DEAE-Sephacel $(100 \mu \mathrm{l}$ beads/100 mg starting material; GE Life Sciences) or a comparable weak anion exchange matrix. This can be done as a batch absorption or as a column. Wash with 10 column volumes of phosphate buffered saline (PBS) followed by 10 column volumes of PBS $(0.25 \mathrm{M} \mathrm{NaCl})$ and elution with 10 column volumes of PBS $(2 \mathrm{M} \mathrm{NaCl})$. Desalt samples and freeze dry. Samples can be stored at $-20^{\circ} \mathrm{C}$.

3. After the first weak anion exchange step, the samples should be reconstituted in $100 \mu \mathrm{l}$ of HPLC-grade water and passed through a 5000 MWCO spin filter to remove any impurities that were not removed in the previous steps that may affect subsequent enzyme and labeling steps.

4. Digestion and removal of contaminating molecules is achieved by the sequential addition of enzymes, followed by weak anion exchange chromatography and desalting. Common choices are DNase, RNase, chondroitin $\mathrm{ABC}$ lyase, neuraminidase, keratanase, hyaluronidase, and proteases, depending on the molecule and level of purity required. 
The RIP method is much faster than previous methods, with samples ready for initial weak anion exchange chromatography in as little as $30 \mathrm{~min}$ and ready for many structural analyses in 2 days (Guimond et al., 2009). It also requires only one transfer before the first weak anion exchange step, thus minimizing sample loss. The weak anion exchange step and subsequent enzyme steps are common to all methods of purification. This method can also be used to isolate other GAGs by altering the enzymes used in the additional purification step. It can also be used on cultured cells. The main disadvantage is the nature of the phenol/chloroform limits the method to small amounts of tissue (up to $1 \mathrm{~g}$ ) to avoid the handling and accumulation of large amounts of chemical waste. Figure 4.1 shows an example of analysis of HS derived from mouse tissues by the RIP method.

\subsection{Profiling disaccharide composition}

The most common method of profiling HS from different sources is the analysis of disaccharides. This type of analysis is an essential first step for characterization of HS. Although common disaccharides are present in different tissues, the proportion of each disaccharide may vary quantitatively, resulting in structural differences between tissues. Disaccharide analysis is most commonly achieved using a mixture of heparinases I, II, and III, derived from Flavobacterium, which are able to cleave HS chains to disaccharide products via an elimination reaction (Hovingh and Linker, 1970; Linhardt et al., 1990). This introduces a C4-C5 unsaturated double bond in the uronic acid residue at the nonreducing end, making direct absorbance measurements possible at $232 \mathrm{~nm}$ (molar extinction coefficient of $5500 \mathrm{M}^{-1} \mathrm{~cm}^{-1}$; Linhardt et al., 1988). Analysis of the resulting disaccharide structures is most commonly undertaken using HPLC separation techniques with UV detection.

However, extraction of HS from small amounts of cells or tissues often produces only small quantities of purified HS sample, making more sensitive analysis techniques essential. High sensitivity detection can be achieved by labeling the products of heparinase digestion, with newly created reducing ends, with fluorescent tags having amine or hydrazide functional groups. Fluorophores which have been coupled to HS disaccharide structures include 2-cyanoacetamide (Toyoda et al., 1997), 2-aminoacridone (AMAC; Deakin and Lyon, 2008; Hitchcock et al., 2008a,b; Kitagawa et al., 1995), 2-aminobenzamide (Kinoshita and Sugahara, 1999; Yamada et al., 1999), and 2-aminobenzoic acid (Sato et al., 2005; Turnbull et al., 1999; Volpi et al., 2009). Reported sensitivities are in the picomol range, with enhanced sensitivity possible using laser-induced fluorescence, often coupled to capillary electrophoresis (Hitchcock et al., 2008a; Karamanos et al., 1996; Lamari et al., 1999; Militsopoulou et al., 2002). 

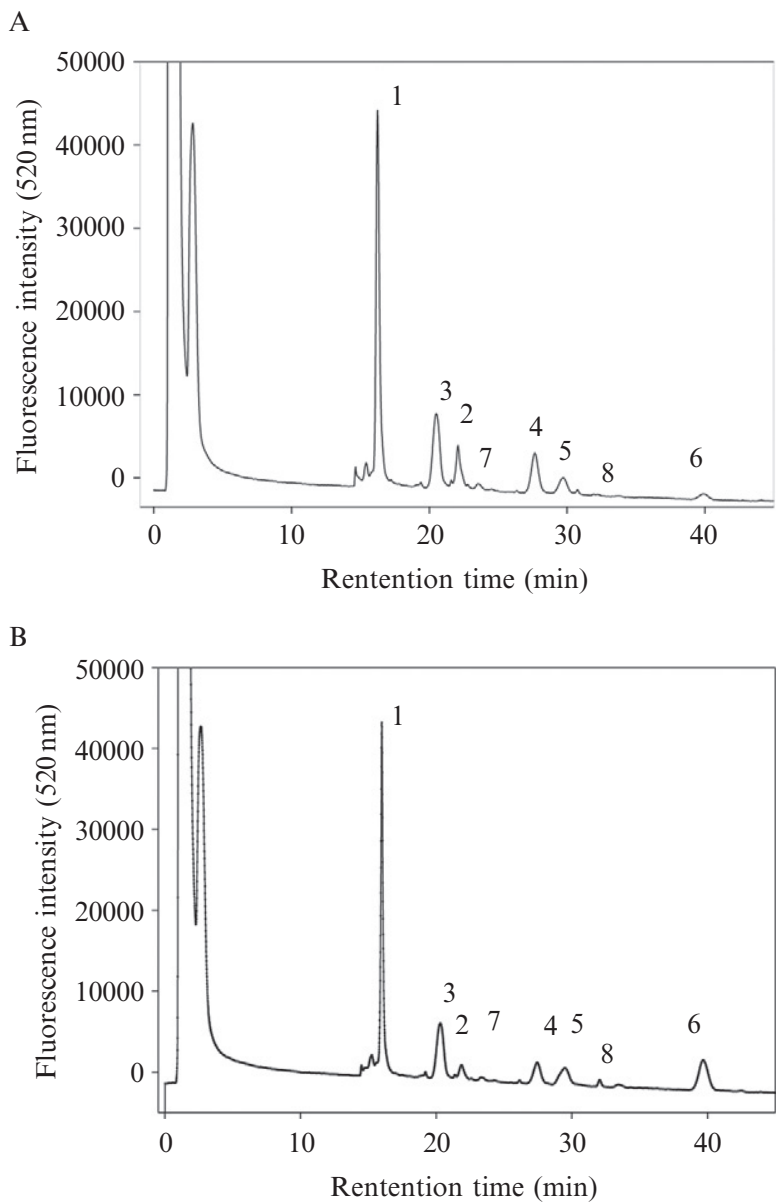

Figure 4.1 Disaccharide compositional profiling of HS from different mouse tissues using RIP extraction and fluorescence detection. HS is purified from $100 \mathrm{mg}$ of each tissue by RIP, digested with heparitinases, labeled with BODIPY hydrazide, and separated by HPLC. Representative data are shown for the tissues: (A) spleen and (B) liver. Disaccharide structures are identified by comparison of retention time with authentic standards (Dextra Ltd). Disaccharide standards are (1) UA-GlcNAc, (2) UA-GlcNAc(6 S), (3) UA-GlcNS, (4) UA-GlcNS(6 S), (5) UA(2 S)-GlcNS, (6) UA (2 S)-GlcNS(6 S), (7) UA(2 S)-GlcNAc, and (8) UA(2 S)-GlcNAc(6 S).

A more recently developed fluorescent tag is 4,4-difluoro-5,7dimethyl-4-bora-3a,4a-diaza-s-indacene-3-propionic acid (BODIPY) hydrazide (Atrih et al., 2009; Skidmore et al., 2006, 2010). This label has several advantages including a detection limit of $\sim 100$ fmol for an HS disaccharide mixture, which provides a $>1000$-fold increase in sensitivity over the use of UV absorbance and 10- to 100-fold increase in 
sensitivity over previous fluorescent labels. The method for labeling HS disaccharides with BODIPY fluorescent tag is described below.

Another recent technology is quantification of disaccharides using offline and online mass spectrometry. The advantages of mass spectrometry are accurate molecular mass confirming the compound, as contaminants from extracts can elute at the same position as the known standard on an HPLC system and the other reason being the sensitivity. Even though six of the disaccharides have isomeric structures, by use of collision-induced dissociation (CID), it is possible to differentiate between them. Quantification by off-line mass spectrometry on biological samples has been achieved using tandem MS, since the ratios of CID products giving a complete quantification analysis without the use of standards. Off-line disaccharide analysis takes minutes and requires no chromatography cleanup (Desaire and Leary, 1999, 2000; Saad and Leary, 2003). Online mass spectrometry has advantages over off-line due to the chromatographic separation; graphitized carbon columns and hydrophilic interaction liquid chromatography (HILIC) may not give full disaccharide separation (but can provide analysis with reference to standards), whereas reverse-phase ion pairing (RPIP) is able to separate all eight common disaccharides, though the ion pairing reagents can cause a small decrease in sensitivity and quality of the spectrum (Zhang et al., 2009). LC-MS using RPIP has also been used for quantitation of disaccharides reductively labeled with aniline-containing stable isotopes (Lawrence et al., 2008).

\subsubsection{Fluorescence HPLC analysis of HS disaccharide composition using BODIPY label}

1. Tissue and cell samples are prepared using the RIP protocol, as described above (Guimond et al., 2009).

2. A preclearing step is carried out to remove low MW contaminants and improve labeling efficiency. Samples are aliquoted into Ultrafree 0.5 spin filters (NMWL $5 \mathrm{kDa}$; Millipore) and centrifuged for $5 \mathrm{~min}$ at $12,000 \mathrm{rpm}$.

3. HS oligosaccharides are digested into disaccharides using a mixture of heparinases I, II, and III (Ibex Ltd.). Complete digestion with heparinase enzymes is achieved by incubating at $37^{\circ} \mathrm{C}$ using initial digestion with heparinase I for $2 \mathrm{~h}$, followed by heparinase III for $2 \mathrm{~h}$ and finally addition of heparinase II, with an overnight incubation. Heparinase enzymes were used at $2.5 \mathrm{mU}$ each (in $10 \mu \mathrm{l}$ of $5 \times$ heparinase buffer, $500 \mathrm{~m} M$ sodium acetate, $0.5 \mathrm{~m} M$ calcium acetate, $\mathrm{pH}$ 7.0). Total volume used is typically $50 \mu \mathrm{l}$, and these conditions are suitable for digestion of up to $1 \mathrm{mg}$ of sample.

4. For reducing-end labeling with the BODIPY dye, samples are initially lyophilized and centrifuged in a 500- $\mu$ l Eppendorf tube. For the labeling 
steps, $10 \mu \mathrm{l}$ of $5 \mathrm{mg} / \mathrm{ml}$ BODIPY hydrazide in methanol is added to the lyophilized sample. Methanol is evaporated using a vacuum centrifuge set at $36{ }^{\circ} \mathrm{C}$ for $30 \mathrm{~min}$.

5. The labeling reaction is carried out in dimethyl sulfoxide (DMSO): glacial acetic acid (17:3, v/v) and incubated at RT for $4 \mathrm{~h}$.

6. The imine (Schiff's base) structures are then reduced to stable derivatives by incubating with $5 \mu \mathrm{l}$ of $1 \mathrm{M}$ sodium borohydride solution (SigmaAldrich) for $30 \mathrm{~min}$ at RT.

7. Samples are then flash frozen using liquid nitrogen and lyophilized. Before separation and analysis, samples are reconstituted with DMSO: water solution $(1: 1, \mathrm{v} / \mathrm{v})$ and resuspended in sample loading solution $(150 \mathrm{mM} \mathrm{NaOH})$.

8. BODIPY-labeled unsaturated HS disaccharides are separated and analyzed using a linear sodium chloride gradient over an isocratic sodium hydroxide solution mobile phase, using a Propac PA1 column (Dionex) on an HPLC system. The column is first equilibrated in sample loading solution $(150 \mathrm{mM} \mathrm{NaOH})$. The fluorescently labeled disaccharides are then loaded using $150 \mathrm{mM} \mathrm{NaOH}$ eluent, with a $10-$ to 20 -min wash step during which the free label elutes and baseline fluorescence levels are restored. The disaccharides are then eluted using a linear gradient of $0-1 M$ sodium chloride (in $150 \mathrm{~m} M \mathrm{NaOH}$ ), over $30 \mathrm{~min}$ at a flow rate of $2 \mathrm{ml} / \mathrm{min}$. Fluorescence measurements are recorded using in-line fluorescent detection at an excitation wavelength of $488 \mathrm{~nm}$ and an emission wavelength of $520 \mathrm{~nm}$. The column is washed using $2 \mathrm{M} \mathrm{NaCl}$ in $300 \mathrm{mM} \mathrm{NaOH}$.

This approach has been used to rapidly profile the disaccharide composition of tissue HS and small amounts of HS from cell culture (Guimond et al., 2009). An example of disaccharide compositional profiling of HS from different mouse tissues using RIP extraction, BODIPY labeling, and strong anion exchange (SAX)-HPLC with fluorescence detection is shown in Fig. 4.1. Previously calculated correction factors are applied to quantitate the observed disaccharides, since there are differences in efficiency of labeling (Skidmore et al., 2006).

\subsection{Profiling HS oligosaccharides}

Following disaccharide compositional analysis, the next stage is to examine the structural profiles of larger oligosaccharides obtained by partial cleavage of HS chains, in order to provide insights into the higher order domain structure. Previous work has exploited methods including gel electrophoresis (Linhardt et al., 1988; Turnbull and Gallagher 1988), gel filtration (Turnbull and Gallagher, 1990, 1991), and HPLC methods including SAX-HPLC (Guimond and Turnbull, 1999; Powell et al., 2010) and 
reverse-phase HPLC (Thanawiroon and Linhardt, 2003). More recently, strategies to profile differences in oligosaccharide domains have been developed employing online mass spectrometry techniques. These strategies look at the total ion abundances from online separations, which yields information on the structures present, including number and types of monosaccharide units, the presence of unsaturated and saturated uronate residues, number of sulfates, number of acetates, and also presence of linker region structures. However, quantitative comparisons by total ion abundance are not possible, since each structure can give different intensities due to differential ionization properties, and standards are simply not available for all structures. However, comparisons of tissue oligosaccharides with the additional data from tandem MS are quantifiable, by comparison between the B-, C-, and Y-type ions based on the nomenclature of Domon and Costello (1988). This strategy has recently been used to compare differences in total ion abundance oligosaccharide patterns between normal bovine cartilage and diseased adult human cartilage, and agreed with similar findings that the sulfation of CS changes with age (Estrella et al., 2007; Hitchcock et al., 2008b). It has also been used to study differences between HS chains between organs (Staples et al., 2009). Thus, this developing methodology is providing structural insights into the differences between HS from different tissues using microgram amounts of sample.

\subsubsection{Liquid chromatography electrospray mass spectrometry}

Oligosaccharide masses were analyzed using liquid chromatography electrospray mass spectrometry (LC-ESI MS) using graphitized carbon columns.

1. SAX-HPLC-purified HS saccharides were desalted and separated using a porous graphitized carbon column $(100 \mathrm{~mm} \times 0.32 \mathrm{~mm}, 5 \mu \mathrm{m}$; Thermo Hypersil, Runcorn, UK). Eluent A was $10 \mathrm{mM}$ ammonium bicarbonate in HPLC-grade water, and eluent B was $80 \%$ acetonitrile/ $10 \mathrm{~m} M$ ammonium bicarbonate.

2 . The samples of varying concentrations were injected and a linear gradient of 100\% eluent A to $40 \%$ eluent B employed over 40 min at a flow rate of $4 \mu \mathrm{l} / \mathrm{min}$.

3. Elution into the electrospray source of the mass spectrometer (LCQ$\mathrm{XP}+$ Thermo Finnigan) was at a flow rate of $4 \mu \mathrm{l} / \mathrm{h}$, via a $1-\mu \mathrm{m}$ tip heated to $270{ }^{\circ} \mathrm{C}$.

4. The negative ion mass spectrum of the sample was recorded using a spray voltage of $3.5 \mathrm{kV}$.

Measuring the total ion count allows a profile of the separated oligosaccharides to be obtained, for example, allowing comparison of different size-fractionated pools of HS oligosaccharides (Fig. 4.2). The masses of saccharides can be examined in each peak to determine a profile of the 

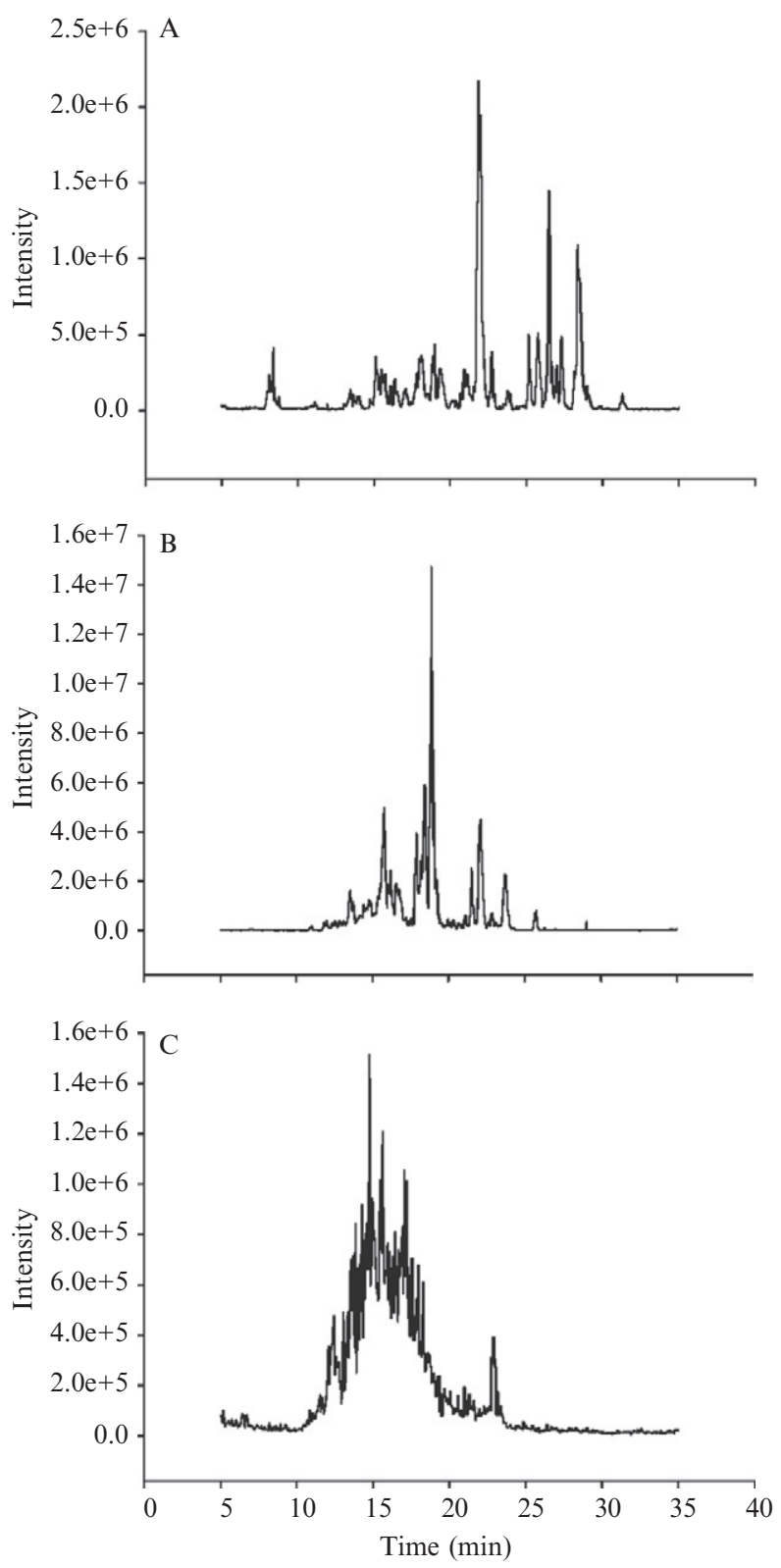

Figure 4.2 Graphitized carbon column LC-MS of size-defined gel filtration fractions from porcine mucosal HS digested with heparinase III. PMHS was digested using heparinase III and the oligosaccharides further separated using gel filtration chromatography on 30 XK16 preparation grade column $(30 \mathrm{~mm} \times 200 \mathrm{~cm}$, bead size $34 \mu \mathrm{m})$. Fractions corresponding to particular size-defined peaks were collected, freeze dried, 
oligosaccharide constituents. This type of analysis can provide accurate profiling information on the types of structures found in a particular HS chain and permits comparisons to be made between samples (Staples et al., 2009).

\subsubsection{Software tools for HS oligosaccharide characterization}

The analysis of GAGs is most often undertaken using HPLC and mass spectrometry techniques. HPLC techniques alone provide constructive data via quantitative compositional analysis, and also comparative profiling, and the latter can be supported by mathematical methods for chemogenic comparisons (Puvirajesinghe et al., 2009). More recently, a leading technique for oligosaccharide profiling, compositional analysis, and identification of rare structures is mass spectrometry. Both ESI and MALDI (Laremore et al., 2007; Tissot et al., 2007) have been employed, ESI providing soft ionization and LC-MS options for accurate analysis and MALDI providing rapid analysis, particularly for backbone structures. Now that mass spectrometry in this field has developed, a stream of oligosaccharide data are beginning to emerge, following strategies that proteomics have adopted. Consequently, bioinformatics programs for the analysis of mass spectrometry spectra are becoming a valuable asset for data analysis. These programs include HOST (Saad and Leary, 2005) and a modified version of Glycoworkbench adapted for GAG analysis (Tissot et al., 2008), based on the Domon and Costello (1988) nomenclature. HOST is a simple Excel software program which uses a combination of clues from MS, MSMS, and enzymatic digestion. For example, heparinase I and III digestion provide clues to the oligosaccharide sequence because of their specificities, assisting MS and MSMS data collection from the same oligosaccharide products. Both data from MS and tandem MS give clues to the sequence, MS revealing the number of sulfates, acetates, and disaccharide units by the $[\mathrm{M}-\mathrm{H}]-1$ ions and MSMS producing fragmentation patterns based on known comparisons (Saad and Leary, 2005). Combined with compositional analysis, HOST will give a score between 1 and 0 , with 1 being the correct sequence, and 0 being an incorrect sequence. The only other data interpretation software available to date is Glycoworkbench (Ceroni et al., 2008). This software analyses spectra by assigning mass ions for both MALDI and ESI data sets. Analysis of the MSMS spectra is also possible, and gives a graphical representation of all

and subjected to LC-MS analysis using a graphitized carbon column $(100 \mathrm{~mm} \times 0.32 \mathrm{~mm}, 5 \mu \mathrm{m}$; Thermo Hypersil, Runcorn, UK) and an LCQ-XP+ Thermo Finnigan instrument as described in Section 3. Each fraction (A)-(C) was run using the same conditions $0-40 \%$ acetonitrile and $10 \mathrm{mM}$ ammonium bicarbonate. (A) LC-MS of a dp4 fraction, (B) LC-MS of a dp6 fraction, and (C) LC-MS of a dp10 fraction. 
possible cleavage products, in which the user can pick the number of cleavage events. These data sets have all been verified using known heparin and chondroitin oligosaccharides. It can also be used independently to build structures in silico from building blocks, and examine their theoretical fragmentation patterns. With mass spectrometry becoming an established tool for the analysis of GAGs, it may be expected that data production will increase exponentially, with consequent requirements for rapid and automatic interpretation of data.

\subsection{Profiling HS oligosaccharide function}

Natural heparan sulfate (HS) oligosaccharide libraries are an important source for exploring HS structure-activity relationships (SAR) and now permit the development of functional glycomics studies. Libraries of HS oligosaccharides can be produced by partial degradation of tissue-derived HS polysaccharide chains and chromatographic fractionation of the resulting oligosaccharide mixtures (Powell et al., 2010). The initial step in HS oligosaccharides production is partial digestion, for example, with heparinase III (to isolate predominantly the sulfated domains), followed by fractionation based on hydrodynamic volume, using size exclusion chromatography (SEC). Subsequent to SEC fractionation, selected size-defined oligosaccharide pools can be subjected to SAX-HPLC, and the resulting products desalted and quantified. These HS oligosaccharide fractions have been shown to contain purified or partially purified oligosaccharides. A brief protocol is provided below, and a comprehensive protocol has been described by Powell et al. (2010).

\subsubsection{Method for HS oligosaccharide library production}

1. Partial enzyme digestion is performed on a purified HS sample after resuspension in heparinase buffer $[100 \mathrm{~m} M$ sodium acetate, $0.1 \mathrm{~m} M$ calcium acetate $(\mathrm{pH}$ 7.0)]. Trial digestion is conducted first in order to determine a suitable amount of heparinase III to use and the time required for digestion to the required extent. Bulk digestion to completion of $400 \mathrm{mg}$ HS was conducted by heparinase III at $0.1 \mathrm{mU} / \mathrm{mg}$ $(5 \mathrm{mU} / \mathrm{ml})$ for $2 \mathrm{~h}$, then $10 \mathrm{mU}$ heparinase III was added and incubated for at $37^{\circ} \mathrm{C}$ for $22 \mathrm{~h}$, and then further $10 \mathrm{mU}$ was added for $2 \mathrm{~h}$. The reaction was stopped by boiling for $2 \mathrm{~min}$; partially digested saccharides were lyophilized and stored at $-20^{\circ} \mathrm{C}$.

2. SEC was carried out using a Superdex ${ }^{\mathrm{TM}} 30$ column (self-poured Super$\mathrm{dex}^{\mathrm{TM}} 30,16 \mathrm{~mm}$ I.D. $\times 200 \mathrm{~cm}$ length) connected to an AKTA purifier 10 system (GE Healthcare). The flow rate was set at $0.5 \mathrm{ml} /$ min with $0.5 \mathrm{M}$ ammonium hydrogen carbonate and elution was monitored at $\lambda_{\mathrm{abs}}=232 \mathrm{~nm}$. Fractions of $1 \mathrm{ml}$ were collected (typically 
sample elution occurs between 150 and $350 \mathrm{ml}$ of column volume for this column). Fractions were pooled individually according to the selected partially resolved SEC peaks. The pooled fractions were then concentrated by serial cycles of lyophilization and stored at $-20{ }^{\circ} \mathrm{C}$.

3. SAX-HPLC was performed on Shimadzu SCL-10AVP system equipped with a Propac PA1 column $(9 \mathrm{~mm} \times 250 \mathrm{~mm}$, Dionex). An analytical trial run $(\sim 50 \mu \mathrm{g})$ was performed in order to establish where fraction collection was required, followed by preparative fractionation. About

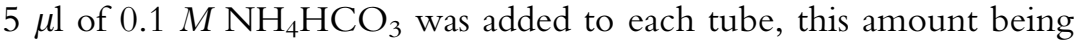
sufficient to neutralize $0.25 \mathrm{ml}$ of elution solvent ( $\mathrm{pH}$ 3.5). Sample (maximum $5 \mathrm{mg}$ ) was made up to a final volume of $0.5 \mathrm{ml}$ in Milli Q $\mathrm{H}_{2} \mathrm{O}$ and injected into the prewashed $1 \mathrm{ml}$ injection loop using a Hamilton syringe. The column was prewashed for 10 min with $2 \mathrm{M}$ $\mathrm{NaCl}$ in water, $\mathrm{pH} 3.5$ (solvent $\mathrm{B}$ ) at $1 \mathrm{ml} / \mathrm{min}$ flow rate and then equilibrated with Milli Q $\mathrm{H}_{2} \mathrm{O}, \mathrm{pH} 3.5$ (solvent A) for $10 \mathrm{~min}$ at the same flow rate. The flow was isocratic in Milli Q $\mathrm{H}_{2} \mathrm{O}(\mathrm{pH} 3.5)$ for $1 \mathrm{~min}$ at flow rate $1 \mathrm{ml} / \mathrm{min}$ for sample loading onto the column. Samples were then eluted with a linear gradient of $0-50 \%$ solvent B $(0-1 \mathrm{M} \mathrm{NaCl})$ over $180 \mathrm{~min}$. The column temperature was set at $40^{\circ} \mathrm{C}$ using column oven. Detection was performed online using a UV detector set at $\lambda_{\text {abs }}=232 \mathrm{~nm}$. Fractions were collected at 15-s intervals $(0.25 \mathrm{ml}$ volume) using a fraction collector calibrated at $1 \mathrm{ml} / \mathrm{ml}$ flow rate, and fraction collector racks were changed at suitable time points where peak elution was absent. Fractions corresponding to the resolved or partially resolved SAX peaks were pooled. The pooled fractions were concentrated by lyophilization and stored at $-20{ }^{\circ} \mathrm{C}$ (Guimond and Turnbull, 1999; Powell et al., 2010).

4. Desalting of fractions was performed on HiPrep ${ }^{\mathrm{TM}} 26 / 10$ desalting column (packed with Sephadex G-25 fine) equilibrated with water on an AKTA purifier 10 system. Elution was monitored at $\lambda_{\mathrm{abs}}=232$ and $215 \mathrm{~nm}$. The fractions corresponding to the oligosaccharide peak (which elutes first) were pooled together, after ensuring that the salt peak (which elutes later) did not overlap with the saccharide peak.

5. Oligosaccharide concentrations were calculated by measuring the absorbance at $\lambda_{\mathrm{abs}}=232 \mathrm{~nm}$ and using the extinction coefficient for the double bond of $5500 \mathrm{~mol}^{-1} \mathrm{~cm}^{-1}$ (Linhardt et al., 1988).

Following library production, it is possible to screen the binding of saccharides using a variety of methods including affinity selection, ELISA assays and optical biosensors (Popplewell et al., 2009; Powell et al., 2004) and more recent technologies such as microarrays (Powell et al., 2009; Zhi et al., 2006, 2008). Saccharides can also be used for studying their effects on protein complex formation, for example, ligand-receptor interactions (Hussain et al., 2006). Perhaps most important, the activity of the saccharides 
can be screened in bioassays, to obtain a bioactivity profile which provides insights into actual SARs. Here, we describe an example of screening modulation of FGF signaling. Cell signaling by FGFs through FGF receptors (FGFRs) depend on HS saccharides (Rapraeger et al., 1991; Yayon et al., 1991). In bioassays, tissue-derived HS oligosaccharides showed diverse selectivity for both activation and inhibition of FGF signaling (Guimond and Turnbull, 1999), using cell proliferation assays with a BaF3 lymphoblastoid cell line which lacks both endogenous HS and FGFRs. These cells can be transfected with specific FGFRs to study FGF signaling (Ornitz et al., 1996) and have been exploited to investigate HS saccharides function (Guimond and Turnbull, 1999; Pye et al., 1998). Established transfectants which express specific FGFR isoforms can be used to screen the abilities of HS saccharides to regulate signaling; in the absence of IL-3 the cells will proliferate in response to appropriate FGFs only in the presence of exogenous activating HS oligosaccharides.

\subsubsection{FGF signaling assay screening using BaF3 cells expressing FGFR1C}

1. BaF3 cells transfected with FGFR1c (Ornitz et al., 1996) were maintained in RPMI 1640 growth medium supplemented with 10\% fetal calf serum, L-glutamine, penicillin $\mathrm{G}$, streptomycin, and $1 \mathrm{ng} / \mathrm{ml} \mathrm{rmIL}-3$ (R\&D systems).

2. FGF-1 or FGF-2 (1 $\mathrm{n} M, \mathrm{R} \& \mathrm{D})$, and selected HS saccharides are prepared in RPMI growth medium. The cells were added to the wells at final density of $10^{4}-10^{5}$ cells $/ \mathrm{ml}$ in the medium without IL-3, and incubated at $37^{\circ} \mathrm{C}$ in $5 \% \mathrm{CO}_{2}$ for $72 \mathrm{~h}$.

3. Cell viability is determined using 3-[4,5-dimethylthiazol-2-yl]-2,5diphenyl-tetrazolium bromide (MTT). MTT was added for $4 \mathrm{~h}$ in the above conditions before solubilization by the addition of $10 \%$ SDS/ $0.01 \mathrm{M} \mathrm{HCl}$ for $16 \mathrm{~h}$. Absorbance at $\lambda_{\text {abs }} 570 \mathrm{~nm}$ is measured using a microtiter plate reader.

An example of the SAX chromatogram profile of an 8-mer fraction of porcine mucosal HS is shown in Fig. 4.3A, demonstrating a complex set of peaks from this tissue. Fractions from the start, middle, and the end of the salt gradient were selected for screening in FGF signaling assays. The selected fractions displayed variant capabilities to activate signaling by FGFR1c in response to FGF-1 (Fig. 4.3B). In addition, the BaF3 bioassay on these fractions was also performed for FGF-2 with same FGFR1c isoform, since it has been documented that FGFR1c has the same proliferative response for both FGF-1 and FGF-2 (Ornitz et al., 1996). The 8-mer SAX subfractions also displayed variant activities with FGF-2, but the profile differed from that for FGF-1 (Fig. 4.3C). In particular, a number of fractions were more active than a heparin 8-mer for activation of FGF-2, 

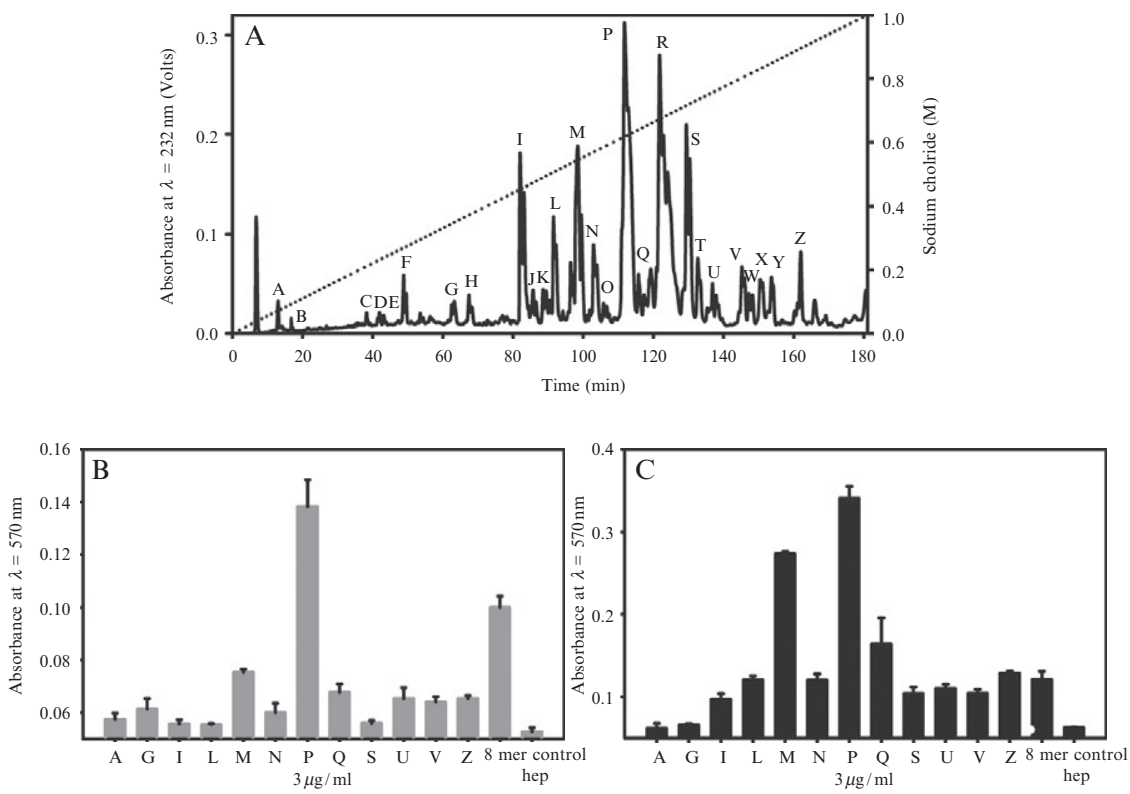

Figure 4.3 Functional profiling of HS saccharides that regulate FGF-1 and FGF-2 through FGFR1c signaling. (A) Porcine mucosal heparan sulfate 8-mer pools obtained by heparinase III digestion followed by SEC were further resolved by high resolution SAX-HPLC, performed on Propac PA1 columns $(9 \mathrm{~mm} \times 250 \mathrm{~mm})$ equilibrated in Milli Q $\mathrm{H}_{2} \mathrm{O}, \mathrm{pH} 3.5$ at flow rate of $1 \mathrm{ml} / \mathrm{min}$. Samples were eluted with a linear gradient of sodium chloride $\mathrm{pH} 3.5$ (0-1 $M$ over $180 \mathrm{~min}$; detection by absorbance at $\lambda=232 \mathrm{~nm}$ ). The figure shows a typical preparative run. Multiple separations of $5 \mathrm{mg}$ per run were performed, and identical peak fractions corresponding to selected peaks were pooled and desalted on HiPrep ${ }^{\mathrm{TM}}$ desalting columns, freeze dried, and quantified. $\mathrm{BaF} 3$ cells were grown in the presence of (B) $1 \mathrm{n} M$ FGF-1 or (C) $1 \mathrm{n} M$ FGF-2. Briefly, $\mathrm{BaF} 3$ cells were grown in the presence of FGFs and HS 8-mer SAX-HPLC fractions at $3 \mu \mathrm{g} / \mathrm{ml}(\mathrm{A}, \mathrm{G}, \mathrm{I}, \mathrm{L}, \mathrm{M}, \mathrm{N}, \mathrm{P}, \mathrm{Q}, \mathrm{S}, \mathrm{U}, \mathrm{V}$, and Z) or an 8-mer heparin saccharide; FGF with no saccharide was the control. Cell proliferation was measured at absorbance at $\lambda=570 \mathrm{~nm}$ using a 3-[4,5-dimethylthiazol-2-yl]-2, 5-diphenyl-tetrazolium bromide (MTT) colorimetric assay. Values are the means of triplicate samples. Error bars represent the standard deviation, and the data are representative of two separate experiments.

whereas only fraction $8 \mathrm{P}$ was more active for FGF-1. These results confirmed previous report that HS saccharides differentially activate FGF signaling (Guimond and Turnbull, 1999), but indicate that the FGF-FGFR ligand activation specificities previously described in the literature (Ornitz et al., 1996) will need to be revised. Finally, it is also possible to select saccharides with defined activities for sequencing (Guimond and Turnbull, 1999; Turnbull et al., 1999), thus permitting detailed SARs to be explored. This is an area in which significant advances can be expected over the next few years. 


\section{Conclusions and Future Perspectives}

The cohort of protocols described above provide one set of approaches for profiling different aspects of HS structure and activity, focusing particularly on disaccharide building blocks and larger oligosaccharide domains, the latter representing the functional units of HS chains. A range of other complementary methods in the literature have also been discussed. Taken together, these provide a new and more comprehensive toolkit to investigate HS structure and activity in a higher throughput manner in selected biological systems. They allow investigation of key questions about the actual structural variation of the heparanome in specific biological contexts and the degree of functional selectivity exerted by these structures in regulating biological processes. The extensive interactome of HS (Ori et al., 2008) provides a significant glycobiology puzzle; its solution clearly requires a move toward systems biology approaches. Further advances in the application of mass spectroscopy to sequencing of $\mathrm{HS}$ saccharides can be expected to make a major contribution, since more complete structure-activity surveys are essential. In addition, development of databases, bioinformatics and computational biology approaches are required to automate, catalog, integrate, and model the ensuing flow of data. We anticipate that the applications of glycomics strategies over the next decade will see major advances in our understanding of the complex biology of HS.

\section{ACKNOWLEDGMENTS}

The authors were funded by grants from the Biotechnology and Biological Sciences Research Council (to J. E. T., Y. A., and S. E. G.), the Engineering and Physical Sciences Research Council (Basic Technology Grant GR/S79268/01 and Basic Technology Translation Grant EP/G037604 to J. E. T.), the Medical Research Council Senior Research Fellowship (to J. E. T.), and the Wellcome Trust (to J. E. T. and S. E. G.). We also thank Dr Andrew Powell, Dr Mark Skidmore, Dr Ed Yates, and Prof. Dave Fernig for stimulating discussions.

\section{REFERENCES}

Atrih, A., Skidmore, M., and Turnbull, J. E. (2009). Labelling heparan sulphate saccharides with chromophore, fluorescence and mass tags for HPLC and MS separations. Methods Mol. Biol. 534, 157-169.

Bishop, J. R., Schuksz, M., and Esko, J. D. (2007). Heparan sulphate proteoglycans finetune mammalian physiology. Nature 446, 1030-1037. 
Brickman, Y., Nurcombe, V., Gallagher, J., Ford, M., and Turnbull, J. E. (1998). Structural modification of FGF-binding HS at a determinative stage of neuroepithelial development. J. Biol. Chem. 273, 4350-4359.

Ceroni, A., Maass, K., Geyer, H., Geyer, R., Dell, A., and Haslam, S. M. (2008). Glycoworkbench: A tool for the computer-assisted annotation of mass spectra of glycans. J. Proteome Res. 7, 1650-1659.

Deakin, J. A., and Lyon, M. (2008). A simplified and sensitive fluorescent method for disaccharide analysis of both heparan sulfate and chondroitin/dermatan sulfates from biological samples. Glycobiology 18, 483-491.

Desaire, H., and Leary, J. (1999). Multicomponent quantification of diasteromeric hexosamine monosaccharides using ion trap tandem mass spectrometry. Anal. Chem. 71, $4142-4147$.

Desaire, H., and Leary, J. (2000). Detection and quantification of the sulfated disaccharides in chrondroitin sulfate by electrospray tandem mass spectrometry. J. Am. Soc. Mass Spectrom. 11, 916-920.

Domon, B., and Costello, C. E. (1988). A systematic nomenclature for carbohydrate fragmentations in FAB-MS/MS spectra of glycoconjugates. Glycoconj. J. 5, 397-409.

Estrella, R. P., Whitelock, J. M., Packer, N. H., and Karlsson, N. G. (2007). Graphitized carbon LC-MS characterisation of the chrondroitin sulfate oligosaccharides of aggrecan. Anal. Chem. 79, 3597-3606.

Ford-Perriss, M., Guimond, S., Greferath, U., Kita, M., Grobe, K., Habuchi, H., Kimata, K., Esko, J. D., Murphy, M., and Turnbull, J. E. (2002). Variant heparan sulfates synthesised in the developing mouse brain differentially regulate FGF signalling. Glycobiology 12, 721-727.

Guimond, S. E., and Turnbull, J. E. (1999). Fibroblast growth factor receptor signalling is dictated by specific heparan sulphate saccharides. Curr. Biol. 9, 1343-1346.

Guimond, S. E., Puvirajesinghe, T. M., Skidmore, M. A., Kalus, I., Dierks, T., Yates, E. A., and Turnbull, J. E. (2009). Rapid purification and high sensitivity analysis of heparan sulfate from cells and tissues: Toward glycomics profiling. J. Biol. Chem. 284, 25714-25722.

Hitchcock, A. M., Bowman, M. J., Staples, G. O., and Zaia, J. (2008a). Improved workup for glycosaminoglycans disaccharide analysis using CE with LIF detection. Electrophoresis 29, 4538-4548.

Hitchcock, A. M., Yates, K. E., Costello, C. E., and Zaia, J. (2008b). Comparative glycomics of connective tissue glycosaminoglycans. Proteomics 8, 1384-1397.

Hovingh, P., and Linker, A. (1970). The enzymatic degradation of heparin and heparitin sulfate. 3. Purification of a heparitinase and a heparinase from flavobacteria. J. Biol. Chem. 245, 6170-6175.

Hussain, S., Piper, M., Fukuhara, N., Strochlic, L., Cho, G., Howitt, J. A., Ahmed, Y., Powell, A. K., Turnbull, J. E., Holt, C. E., and Hohenester, E. (2006). A molecular mechanism for the heparan sulfate dependence of slit-robo signaling. J. Biol. Chem. 281, 39693-39698.

Jayson, G., Lyon, M., Paraskeva, C., Turnbull, J. E., Deakin, J. A., and Gallagher, J. T. (1998). Heparan sulfate undergoes specific structural changes during the progression from adenoma to carcinoma, in vitro. J. Biol. Chem. 273, 51-57.

Karamanos, N. K., Vanky, P., Tzanakakis, G. N., and Hjerpe, A. (1996). High performance capillary electrophoresis method to characterize heparin and heparan sulfate disaccharides. Electrophoresis 391-395.

Kato, M., Wang, H.-M., Bernfield, M., Gallagher, J. T., and Turnbull, J. E. (1994). Cell surface syndecan-1 on distinct cell types differs in fine structure and ligand binding of its HS chains. J. Biol. Chem. 269, 18881-18890. 
Kinoshita, A., and Sugahara, K. (1999). Microanalysis of glycosaminoglycan-derived oligosaccharides labeled with a fluorophore 2 -aminobenzamide by high-performance liquid chromatography: Application to disaccharide composition analysis and exosequencing of oligosaccharides. Anal. Biochem. 269, 367-378.

Kitagawa, H., Kinoshita, A., and Sugahara, K. (1995). Microanalysis of glycosaminoglycanderived disaccharides labeled with the fluorophore 2 -aminoacridone by capillary electrophoresis and high-performance liquid chromatography. Anal. Biochem. 232, 114-121.

Lamari, F., Theocharis, A., Hjerpe, A., and Karamanos, N. K. (1999). Ultrasensitive capillary electrophoresis of sulfated disaccharides in chrondroitin/dermatan sulfate by laserinduced fluorescence after derivatization with 2-aminoacridone. Chromatogr. B Biomed. Sci. Appl. 730, 129-133.

Lander, A. D., and Selleck, S. B. (2000). The elusive functions of proteoglycans: In vivo veritas. J. Cell Biol. 148, 227-232.

Lander, A., Nakato, H., Selleck, S. B., Turnbull, J. E., and Coath, C. (1999). Cell surface proteoglycans and growth factor signalling in development. In "HFSP Workshop Reports," (J. Altman, ed.), Vol. VI, Human Frontier Science Program, HFSP Press.

Laremore, T. N., Murugesan, S., Park, T. J., Avci, F. Y., Zagorevski, D. V., and Linhardt, R. J. (2007). Matrix-assisted laser desorption/ionization mass spectrometric analysis of uncomplexed highly sulfated oligosaccharides using ionic liquid matrices. Anal. Chem. 78, 1774-1779.

Lawrence, R., Olson, S. K., Steele, R. E., Wang, L., Warrior, R., Cummings, R. D., and Esko, J. D. (2008). Evolutionary differences in glycosaminoglycan fine structure detected by quantitative glycan reductive isotope labeling. J. Biol. Chem. 283, 33674-33684.

Lindahl, U., and Ping, J.-P. (2009). Interactions between heparan sulphate and proteinsDesign and functional implications. Int. Rev. Cell Mol. Biol. 276, 105-159.

Lindahl, U., Kusche-Gullberg, M., and Kjellen, L. (1998). Regulated diversity of heparan sulphate. J. Biol. Chem. 273, 24979-24982.

Linhardt, R. J., Rice, K. G., Kim, Y. S., Lohse, D. L., Wang, H. M., and Loganathan, D. (1988). Mapping and quantification of the major oligosaccharide components of heparin. Biochem. J. 254, 781-787.

Linhardt, R. J., Turnbull, J. E., Wang, H., Loganathan, D., and Gallagher, J. T. (1990). Examination of the substrate specificity of heparin and heparan sulphate lyases. Biochemistry 29, 2611-2617.

Maccarana, M., Sakura, Y., Tawada, A., Yoshida, K., and Lindahl, U. (1996). Domain structure of heparan sulphates from bovine organs. J. Biol. Chem. 271, 17804-17810.

Militsopoulou, M., Lamari, F. N., Hjerpe, A., and Karamanos, N. K. (2002). Determination of twelve heparin- and heparan sulfate-derived disaccharides as 2-aminoacridone derivatives by capillary zone electrophoresis using ultraviolet and laser-induced fluorescence detection. Electrophoresis 23, 1104-1109.

Nugent, M. A. (2000). Heparin sequencing brings structure to the function of complex oligosaccharides. Proc. Natl. Acad. Sci. USA 97, 10301-10303.

Ori, A., Wilkinson, M. C., and Fernig, D. G. (2008). The heparanome and regulation of cell function: Structures, functions and challenges. Front. Biosci. 13, 4309-4338.

Ornitz, D. M., Xu, J., Colvin, J. S., Mcewen, D. G., Macarthur, C. A., Coulier, F., Gao, G., and Goldfarb, M. (1996). Receptor specificity of the fibroblast growth factor family. J. Biol. Chem. 271, 15292-15297.

Popplewell, J. F., Swann, M. J., Ahmed, Y., Turnbull, J. E., and Fernig, D. G. (2009). Fabrication of carbohydrate surfaces using non-derivatized oligosaccharides, and their application to measuring the assembly of sugar-protein complexes. Chembiochem $\mathbf{1 0}$, 1218-1226. 
Powell, A. K., Yates, E. A., Fernig, D. G., and Turnbull, J. E. (2004). Interaction of heparin/ heparan sulfate with proteins: Appraisal of structural factors and experimental approaches. Glycobiology 14, 17-30.

Powell, A., Zhi, Z., and Turnbull, J. E. (2009). Saccharide microarrays for high-throughput interrogation of glycan-protein binding interactions. Methods Mol. Biol. 534, 313-329.

Powell, A. K., Ahmed, Y. A., Yates, E. A., and Turnbull, J. E. (2010). Generating heparan sulfate saccharide libraries for glycomics applications. Nat. Protoc. 5, 821-833.

Puvirajesinghe, T., Guimond, S. E., Turnbull, J. E., Guenneau, S., and Movchan, A. B. (2009). Chemogenic analysis for comparison of heparan sulphate oligosaccharides. J. R. Soc. Interface 6, 997-1004.

Pye, D. A., Vives, R. R., Turnbull, J. E., Hyde, P., and Gallagher, J. T. (1998). Heparan sulfate oligosaccharides require 6-O-sulfation for promotion of basic fibroblast growth factor mitogenic activity. J. Biol. Chem. 273, 22936-22942.

Rapraeger, A. C., Krufka, A., and Olwin, B. B. (1991). Requirement of heparan sulfate for bFGF-mediated fibroblast growth and myoblast differentiation. Science 252, 1705-1708.

Saad, O., and Leary, J. (2003). Compositional analysis and quantification of heparin and heparan sulfate by electrospray ionization ion trap mass spectrometry. Anal. Chem. 75, 2985-2995.

Saad, O. M., and Leary, J. A. (2004). Delineating mechanisms of dissociation for isomeric heparin disaccharides using isotope labeling and ion trap tandem mass spectrometry. J. Am. Soc. Mass Spectrom. 15, 1274-1286.

Saad, O. M., and Leary, J. A. (2005). Heparin sequencing using enzymatic digestion and ESI-MSn with HOST: A heparin/HS oligosaccharide sequencing tool. Anal. Chem. 77, 5902-5911.

Sanderson, R. D., Turnbull, J. E., Gallagher, J. T., and Lander, A. D. (1994). Fine structure of HS regulates cell syndecan-1 function and cell behaviour. J. Biol. Chem. 269, 13100-13106.

Sato, K., Okubo, A., and Yamazaki, S. (2005). Separation of 2-aminobenzoic acid-derivatized glycosaminoglycans and asparagine-linked glycans by capillary electrophoresis. Anal. Sci. 21, 21-24.

Schmidt, A., Skaletz-Rorowski, A., and Buddecke, E. (1995). Basic fibroblast growth factor controls the expression and molecular structure of heparan sulfate in corneal endothelial cells. Eur. J. Biochem. 234, 479-484.

Skidmore, M. A., Guimond, S. E., Dumax-Vorzet, A. F., Atrih, A., Yates, E. A., and Turnbull, J. E. (2006). High sensitivity separation and detection of heparan sulfate disaccharides. J. Chromatogr. A 1135, 52-56.

Skidmore, M. A., Guimond, S. E., Dumax-Vorzet, A., Yates, E. A., and Turnbull, J. E. (2010). Disaccharide compositional analysis of heparan sulphate and heparin polysaccharides using UV or high sensitivity fluorescence (BODIPY) detection. Nat. Protoc. (in press).

Staples, G. O., Bowman, M. J., Costello, C. E., Hitchcock, A. M., Lau, J. M., Leymarie, N., Miller, C., Niamy, H., Shi, X., and Zaia, J. (2009). A chip-based amide-HILIC LC/MS platform for glycosaminoglycans glycomics profiling. Proteomics 9, 686-695.

Thanawiroon, C., and Linhardt, R. J. (2003). Separation of complex mixture of heparin derived oligosaccharides using reversed-phase high performance liquid chromatography. J. Chromatogr. A 1014, 214-223.

Tissot, B., Gasiunas, N., Powell, A. K., Ahmed, Y., Zhi, Z., Haslam, S. M., Morris, H. R., Turnbull, J. E., Gallagher, J. T., and Dell, A. (2007). Towards GAG glycomics: Analysis of highly sulfated heparins by MALDI-TOF mass spectrometry. Glycobiology 17, 972-982. 
Tissot, B., Ceroni, A., Powell, A. K., Morris, H. R., Yates, E. A., Turnbull, J. E., Gallagher, J. T., Dell, A., and Haslam, S. M. (2008). Software tool for the structural determination of glycosaminoglycans by mass spectrometry. Anal. Chem. 80, 9204-9212.

Toyoda, H., Nagashima, T., Hirata, R., Toida, T., and Imanari, T. (1997). Sensitive highperformance liquid chromatographic method with fluorometric detection for the determination of heparin and heparan sulfate in biological samples: Application to human urinary heparan sulfate. J. Chromatogr. B 704, 19-24.

Turnbull, J. E., and Field, R. (2007). Emerging Glycomics Technologies. Nat. Chem. Biol. 3, 74-77.

Turnbull, J. E., and Gallagher, J. T. (1988). Oligosaccharide mapping of heparan sulphate by polyacrylamide-gradient-gel electrophoresis and electrotransfer to nylon membrane. Biochem. J. 251, 597-608.

Turnbull, J. E., and Gallagher, J. T. (1990). Molecular organisation of heparan sulphate from human skin fibroblasts. Biochem. J. 265, 715-724.

Turnbull, J. E., and Gallagher, J. T. (1991). Distribution of iduronate-2-sulphate residues in heparan sulphate: Evidence for an ordered polymeric structure. Biochem. J. 273, 553-559.

Turnbull, J. E., Hopwood, J. J., and Gallagher, J. T. (1999). A strategy for rapid sequencing of heparan sulfate and heparin saccharides. Proc. Natl. Acad. Sci. USA 96, 2698-2703.

Turnbull, J. E., Powell, A., and Guimond, S. E. (2001). Heparan sulphate: Decoding a dynamic multifunctional cell regulator. Trends Cell Biol. 11, 75-82.

Volpi, N., Maccari, F., and Linhardt, R. J. (2009). Quantitative capillary electrophoresis determination of oversulfated chondroitin sulfate as a contaminant in heparin preparations. Anal. Biochem. 388, 140-145.

Yamada, S., Van Die, I., Van den Eijnden, D. H., Yokota, A., Kitagawa, H., and Sugahara, K. (1999). Demonstration of glycosaminoglycans in Caenorhabditis elegans. FEBS Lett. 459, 327-331.

Yanagishita, M., and Hascall, V. C. (1984). Metabolism of proteoglycans in rat ovarian granulosa cell culture. Multiple intracellular degradative pathways and the effect of chloroquine. J. Biol. Chem. 259, 10270-10283.

Yayon, A., Klagsbrun, M., Esko, J. D., Leder, P., and Ornitz, D. M. (1991). Cell surface, heparin-like molecules are required for binding of basic fibroblast growth factor to its high affinity receptor. Cell 64, 841-848.

Zhang, Z., Xie, J., Liu, H., Liu, J., and Linhardt, R. (2009). Quantification of heparan sulfate disaccharides using ion-pairing reversed-phase microflow high-performance liquid chromatography with electrospray ionization trap mass spectrometry. Anal. Chem. 81, 4349-4355.

Zhi, Z., Powell, A., and Turnbull, J. E. (2006). Fabrication of carbohydrate microarray on gold surface: Direct attachment of non-derivatized oligosaccharides to hydrazide-derivatized self-assembled monolayer. Anal. Chem. 78, 4786-4793.

Zhi, Z., Laurent, N., Powell, A. K., Voglmeir, J., Wright, A., Karamanska, R., Fais, M., Blackburn, J., Crocker, P. R., Russell, D., Flitsch, S., Field, R., et al. (2008). A versatile gold surface approach for fabrication and interrogation of glycoarrays. Chembiochem $\mathbf{9}$, 1568-1575. 